$$
\begin{array}{r}
\text { BAHSERIKOV } \\
\text { CENTRO DE MEDIC } \\
\text { INDÍGENA DA AMAZÔ } \\
\text { CONCEPÇÕES E PRÁTI } \\
\text { DE SAÚDE INDÍG }
\end{array}
$$




\section{BAHSERIKOWI - CENTRO DE MEDICINA INDÍGENA DA AMAZÔNIA: CONCEPÇÕES E PRÁTICAS DE SAUUDE INDÍGENA}




\title{
BAHSERIKOWI - CENTRO DE MEDICINA INDÍGENA DA AMAZÔNIA: CONCEPÇÕES E PRÁTICAS DE SAÚDE INDÍGENA
}

\section{Resumo}

Pretende-se neste artigo refletir aspectos de conflitos ontológicos entre o modelo de conhecimento indígena e o modelo universal de conhecimento, a partir de uma experiencia desagradável, para não dizer discriminatória, vivenciada durante o ano de 2009. Por outro lado, este fato acabou por servir de embião para criação do Bahserikowi: Centro de Medicina Indígena. A apresentação visa basicamente refletir como o imaginário construído pelas sociedades sobre o "índio", sobretudo a classe médica, tem uma visão equivocada sobre conhecimentos e práticas indígenas. $\mathrm{O}$ modelo de conhecimento indígena considera que a doença e saúde não se restringem ao aspecto biológico. Antes, ao contrário, envolvem aspectos cosmopolíticos que condicionam a prática da boa saúde. Sai, assim, do entendimento restrito de algo biológico e conecta o indivíduo numa teia de relações com outros seres, com os waimahsã, com os animais, os especialistas, com seus parentes e outras pessoas.

Palavras-chave: Bahsserikowi, Biomedicina, Babsese

\section{BAHSERIKOWI - INDIGENOUS MEDICINE CENTER OF THE AMAZON: INDIGENOUS HEALTH CONCEPTIONS AND PRACTICES}

\begin{abstract}
This manuscript intends to reflect on aspects of ontological conflicts between the indigenous knowledge model and the universal knowledge model, based on an unpleasant, not to mention discriminatory, experience during 2009. On the other hand, this fact served as an inspiration for the creation of Bahserikowi: Indigenous Medicine Center. The presentation aims, basically, to reflect on how the imaginary constructed by societies about the "Indian", especially the medical class, has a misconception about indigenous knowledge and practices. The indigenous knowledge model considers that disease and health are not restricted to the biological aspect. Rather, on the contrary,
\end{abstract}


they involve cosmopolitical aspects which condition the practice of good health. It, thus, comes out of the restricted understanding of something biological and it connects the individual in a net of relations with other beings, with the waimahsã, with the animals, the specialists, with their relatives and other people.

Keywords: Bahsserikowi, biomedicine, Bahsese.

\section{BAHSERIKOWI - CENTRO DE MEDICINA INDÍGENA DE LA AMAZONIA: CONCEPCIONES Y PRÁCTICAS DE SALUD INDÍGENA}

\section{Resumen}

Este artículo pretende reflejar aspectos de conflictos ontológicos entre el modelo de conocimiento indígena y el modelo universal de conocimiento, a partir de una experiencia desagradable, por no decir discriminatoria, vivenciada durante el año 2009. Por otro lado, este hecho terminó sirviendo de embrión para la creación del Bahserikowi: Centro de Medicina Indígena. La presentación básicamente considera cómo el imaginario construido por las sociedades sobre el "indio", sobre todo la clase media, tiene una visión equivocada sobre conocimientos y prácticas indígenas. El modelo de conocimiento indígena considera que la enfermedad y la salud no se restringen al aspecto biológico. Al contrario, involucra aspectos cosmopolíticos que condicionan la práctica de la buena salud. Se sale, así, del entendimiento restringido de algo biológico y conecta al individuo en una red de relaciones con otros seres, con los waimahsã, con los animales, los especialistas, con sus parientes y otras personas.

Palabras clave: Babsserikowi, Biomedicina, Babsese.

João Paulo Lima Barreto ${ }^{1}$

jplbarreto@gmail.com 
Este artigo discute basicamente conflitos entre modelos biomédicos e conceções de doenças e práticas de saúde a partir da perspetiva indígena na região do Alto Rio Negro/AM. O objetivo é apontar como o modo de pensar a doença é também o modo de pensar o equilíbrio e desequilíbrio do cosmos, portanto não tendo como pressuposto a noção de indivíduo e os limites de espaços físicos ou corpos meramente orgânicos. A partir dessa discussão, a intenção é problematizar políticas públicas de saúde prestadas aos povos indígenas e o lugar dos especialistas indígenas em processos de cura, com foco na implementação do Centro de Medicina Indígena da Amazônia, sediado na cidade de Manaus ${ }^{2}$.

Como capital do Estado do Amazonas, Manaus concentra a maior diversidade de povos indígenas como Arapasso, Apurinã, Baniwa, Bará, Barassana, Baré, Deni, Dessano, Hupda, Itana, Jamamadi, Yanomami, Yskarino, Kambeba, Kokama, Kanamari, Karapãna, Korubo, Kubeo, Satere-Maué, Manchineri, Mati, Maraguá, Marubo, Miranha, Mirititapuia, Munduruku, Mura, Piratapuya, Tariano, Tikuna, Tukano, Tuyuka, Way-way e Wanano, Maraguá que somam, segundo estimativa da FUNAI de Manaus, uma população de 30 mil indivíduos aproximadamente.

O Centro de Medicina Indígena da Amazônia foi fundado no dia 06 de junho de 2017, por minha iniciativa, como membro do povo Yepamahsã (Tukano), e com apoio dos Kumuã (pajés) Manoel Lima, da etnia Tuyuca, Ovídio Lemos Barreto, e José Maria Barreto, ambos da etnia Yepamahsã, e com a colaboração de jovens indígenas Ivan Barreto, Cleofa Barreto, Josivan Barreto, da etnia Yepamahsã e da jovem indígena Carla Fernandes, da etnia Dessana. O centro conta com a parceria da Coordenação das Organizações Indígenas da Amazônia Brasileira (Coiab), do Núcleo de Estudo da Amazônia Indígena (NEAI/UFAM), além do apoio da agência de comunicação Amazônia Real.

A iniciativa é fruto de experiências pessoais e familiares ao longo de doze anos, algumas negativas e outras positivas, no confronto entre o modelo de conhecimentos indígenas e a ciência, sobretudo com o modelo de tratamento de saúde biomédico. Muitos conceitos criados pela ciência para entender ou "desvendar" o sistema de conhecimentos indígenas produziram um imaginário distorcido e muito distante das concepções indígenas. Por exemplo, o pajé costuma ser imaginado como um velhinho que tem poder de transitar entre o universo dos deuses ou dos mortos, que conversa com os animais, plantas ou minerais para adquirir poderes sobrenaturais. É um imaginário muito exotizante que a mídia ou os livros didáticos, além da própria ciência, difunde na sociedade não indígena. Dessa forma, conceitos como mito, religião, xamanismo, maloca, benzimento, magia e feitiçaria têm conduzido a um imaginário equivocado e distanciado das epistemologias propriamente indígenas.

A estrutura do texto inicia com um acontecimento que motivou a criação do centro, para então aprofundar concepções indígenas sobre o cosmos e 
seus habitantes, assim como a formação e atuação de especialistas em curas entre os yepamahsã.

\section{A BIOMEDICINA NA FACA}

A criação do Bahserikowi está em conexão com o episódio que aconteceu com minha família, em especial com minha sobrinha. Um acontecimento que, infelizmente, está longe de ser um fato isolado. Muitos casos semelhantes têm acontecido nos hospitais de Manaus, com os pacientes indígenas.

Em janeiro de 2009, minha sobrinha Luciane Trurriyo Barreto, encaminhada pelo DSEI do município de São Gabriel da Cachoeira e acompanhada de seu pai José Maria Barreto, veio à capital do Amazonas para tratamento, depois de ser picada por uma cobra. Apresentando grave estado de saúde, logo foi internada. Passados dois dias, meu irmão, José Maria, me ligou desesperado do hospital, me dizendo que os médicos tinham decidido amputar o pé da minha sobrinha. O diagnóstico do médico considerava que a situação era grave e que o pé ferido estava necrosando muito rapidamente, e essa situação colocava em risco a vida da menina. Meu irmão me falava também que os médicos já estavam fazendo "cirurgia vascular", e que toda pele da palma do pé tinha sido retirada. Isso causava desespero tanto dela quanto do seu pai.

Nessa época, eu estava para concluir o curso de graduação em Filosofia pela Universidade Federal do Amazonas - UFAM, e ao mesmo tempo cursava Direito na Universidade do Estado
Amazonas - UEA. Com a notícia da amputação do pé da minha sobrinha, fui ao encontro do meu irmão. Desesperado, ele relatava os fatos e falava da pressão e ameaça que a assistente social e a equipe médica faziam para ele consentir a amputação, dizendo que a filha dele morreria em menos de três dias caso não fosse realizado tal procedimento. Meu irmão buscava forças para convencer os médicos de que aquilo não era necessário, e sugeria realizar um tratamento à base do bahsese e ervas medicinais.

Antes disso, porém, fomos consultar nossos especialistas kumuã yepamahsã (Tukano). Dois eram meus tios, outro meu pai. Eles nos garantiam que não era necessário amputar naquele momento, era preciso recorrer ao tratamento com bahsese e plantas medicinais, que eles mesmos garantiam fazer. Estavam certos também que tais procedimentos, no entanto, não excluíam o tratamento médico, que deveria continuar, mas sem amputação.

Com a garantia dada pelos nossos especialistas, partimos para dialogar com os médicos do hospital. Nossa proposta foi imediatamente rejeitada, e a decisão pela amputação do pé de minha sobrinha foi mantida. Instalou-se aí um grande conflito entre nós e os médicos. Fomos acusados, dentre outras coisas, de obstruir o trabalho médico. Meu irmão foi ameaçado de ser denunciado ao Conselho Tutelar pela assistente social do hospital e pela Casa de Assistência Social ao Índio - CASAI.

Corríamos contra o tempo para adiar a data de amputação, pois estávamos 
decididos a lutar para que o tratamento com bahese e plantas medicinais fosse realizado juntamente com os procedimentos da medicina. Passamos a mobilizar o Ministério Público Federal, e o fato passou a repercutir na mídia. Exigimos outra reunião com a equipe médica. Nesse meio tempo, meu irmão levava remédio à base de planta medicinal e bahsese escondidos dos médicos para a menina no hospital.

Diante da grande repercussão nos meios de comunicação de massa, a equipe médica do hospital aceitou realizar mais uma reunião conosco. Achávamos, com isso, que estava garantido o tratamento conjunto, mas não foi o que aconteceu. $\mathrm{Na}$ sala de reunião, num lado sentou-se a equipe médica, e, no outro, sentamos nós e nossos especialistas. O chefe da equipe médica, sem muita conversa, de modo raivoso e arrogante, dirigiu-se a meu pai perguntando: por que o senhor acha que não deve amputar o pé de sua neta?

Meu pai, sem falar bem o português, começou a responder, dizendo que do ponto de vista dele, como kumu, o pé de sua neta não estava necrosado, pois a cor roxa do pé era uma reação do sangue com o veneno da cobra. O médico, visivelmente irritado, interrompeu a fala de meu pai, e esmurrando na mesa disse - "eu estudei oito anos para ter autoridade para decidir o que é que melhor para um paciente, enquanto o senhor (com muito respeito), não frequentou um dia sequer a medicina". Dizendo isso se retirou, levando consigo toda a equipe.
A partir desse momento nossa luta passou a ser a retirada de minha sobrinha do hospital. Confesso que não foi fácil, pois o tempo todo a equipe médica ameaçava nos processar e sustentava a necessidade de fazer a amputação. Após vários dias, finalmente retiramos a menina do hospital e levamos para a Casa de Apoio do município de São Gabriel da Cachoeira. Lá ela teve acompanhamento e tratamento dos kumuã, à base de bahsese e ervas medicinais, sem interromper os medicamentos, que ficaram sob supervisão de uma técnica de enfermagem.

Com a repercussão do fato na mídia, uma equipe de outro hospital público decidiu convidar-nos para uma conversa. Durante a reunião, nossos especialistas tiveram oportunidade de apresentar suas técnicas e formas de tratamento à base de bahsese e plantas medicinais. Num diálogo bastante sincero, levando em conta os riscos e probabilidades de sucesso, foi feito um acordo formal para o tratamento conjunto. Com tal acordo, a menina foi internada no hospital. Assim, todas as vezes em que as enfermeiras faziam o curativo no pé de minha sobrinha, os kumuã entravam com procedimentos de bahsese.

Como resultado desse esforço, o pé da minha sobrinha não foi amputado, perdendo apenas alguns movimentos como consequência. Hoje ela vive na comunidade/aldeia São Domingos Sávio, no Rio Tiquié, alto Rio Negro, longe da cidade e dos médicos.

No conflito ontológico entre nós e os médicos estava em jogo os conceitos 
formatados acerca dos nossos conhecimentos indígenas, falsos e vagamente formados ou conhecidos por eles. Assim, os médicos do hospital, carregados de um imaginário sobre pajelança e não sei o que mais, achavam que os kumuã entrariam no hospital adornados de cocares, com colares de dentes de onças, pintados, cantando e dançando sob som de tambores e maracás.

As concepções indígenas de doença e saúde não se restringem ao aspecto biológico. Esse é o ponto. Antes o contrário, envolvem aspectos cosmopolíticos que condicionam a prática da boa saúde. Sai, assim, do entendimento restrito de algo biológico e conecta o indivíduo numa teia de relações com outros seres, com os waimahsã, com os animais, os especialistas, com seus parentes e outras pessoas.

Da nossa parte, partimos da ideia de que é preciso somar esforços e dar visibilidade às concepções, técnicas e práticas de tratamento de saúde desenvolvido pelos especialistas indígenas yai, kumuã e baya, doravante chamados de pajés, no mesmo nível do valor médico.

O fato que aconteceu com minha sobrinha Luciane foi minha maior inspiração e incentivo para a criação do Centro de Medicina Indígena da Amazônia. Sua luta e nossa luta, contrapondo a biomedicina, colocando nossas concepções e práticas na mesa de negociação e no mesmo nível de "valor", trouxe um resultado muito positivo, e nos convenceu definitivamente de que era importante ampliar essa luta e nossos valores/conhecimentos indígenas.
Foi com isso, e é com isso em mente que criamos o Centro de Medicina Indígena da Amazônia na cidade de Manaus. Um lugar onde queremos colocar isso em prática, valorizando os especialistas que exercem este ofício, na maioria das vezes alheios e à margem da sociedade como um todo, muitas vezes atendendo o mesmo público, os mesmos pacientes que o um hospital atende. Esse quadro é bastante real em Manaus e seus municípios, sobretudo no município de São Gabriel da Cachoeira, onde a maioria é indígena.

Com a iniciativa, em nenhum momento queremos colocar em questão o modelo oficial de tratamento de saúde. Queremos simplesmente oferecer a oportunidade para as pessoas que acreditam que a saúde perpassa por outras vias de tratamentos terem também o direito de os acessar. Assim, o Centro de Medicina Indígena é mais uma opção, um canal que possibilita ao público uma opção de tratamento por vias de tecnologias indígenas baseadas em outros parâmetros que não os da medicina ocidental.

A proposta é ter o Centro como um espaço de circuito de especialistas indígenas de todos os povos. Mas no momento não temos recurso financeiro para criar essa política. Já tivemos manifestação dos Yanomami, dos Apurinã e Marubo para vir passar um período no Centro atendendo as pessoas. Mas isso implica em ter recurso financeiro para trazê-los e manter eles na cidade e no centro, o que no momento não temos condições, entretanto logo pretendemos alcançar esse objetivo. 
Aqueles que buscam tratamento costumam ficar direito no Centro. Mas há casos que os Kumuã fazem atendimento domiciliar, desde que a pessoa interessada ofereça estrutura, pois ainda não temos condição para transporte de especialistas e estrutura em geral. Não temos nenhum projeto ou vínculo com poder público para disponibilizar o atendimento gratuito aos interessados. Mantemos os especialistas com taxa que cobramos com os tratamentos das pessoas.

A ajuda de custo aos especialistas e aos jovens indígenas colaboradores é dividida de acordo com a arrecadação mensal. E também o mantimento da equipe com transporte, alimentação e pagamento de água, energia, material de limpeza, material de expedientes etc. Assim não se tem salário fixo.

Nesses quatro meses de "funcionamento" do Centro, já passaram mais de 500 pessoas pelo centro, indígenas e não-indígenas, na maioria mulheres, de faixa etária de 30 a 50 anos de idade. Estamos num prédio localizado no centro histórico da cidade, com duas salas de consultas e de tratamento. Temos colabores como atendentes e intérpretes. O protocolo é seguido de diagnóstico, análise de complexidade da doença, tempo de tratamento, restrições alimentares e sexuais em alguns casos e acompanhamento. Há duas principais formas de tratamentos: bahsese (benzimento) e uso de plantas medicinais. Ambas não produzem efeitos colaterais. As pessoas se surpreendem porque não encontram equipamentos sofisticados nas salas de consultas.
Fizemos parceria com uma associação apurinã, de Tapauá, para fornecerem remédio à base de vegetais e animais. Essa associação já vinha desenvolvendo os remédios há mais de 20 anos, com o acompanhamento da UFAM. Em todos os remédios há data de "fabricação" e data de vencimento, o que achamos muito importante para dar segurança às pessoas. Mas nosso projeto é criar viveiros, plantar e produzir farmacopeia indígena. Entretanto, há remédios feitos à base de plantas que é de domínio de alguém, neste caso somente solicitamos seu fornecimento sem aquela pessoa revele seu segredo. Tudo isso está em discussão e experimentação nesses quatros meses de existência do Centro.

O Centro não se restringe apenas à consulta e tratamento de saúde, sendo também um lugar dinamizador e incentivador de novos centros de medicina indígena em outras regiões do Brasil. Dito de modo bastante sucinto, a iniciativa quer contrapor a política de dependência química dos povos indígenas imposta pela política de tratamento de saúde oficial, promovendo um debate sobre outras formas de tratamento e concepções sobre saúde.

Neste sentido, o Babserikowi visa, de forma ampla, constituir um espaço de diálogo com outros saberes, sejam eles indígenas ou não, a fim de promover o intercâmbio cultural e a produção de conhecimento na área da saúde e outros campos. $\mathrm{Na}$ concepção indígena existe uma distinção muito clara daquelas doenças que a biomedicina 
pode resolver, sobretudo com sistema de cirurgias e outras doenças que somente os especialistas indígenas podem fazer tratamento (cura). Nesse sentido, os dois conhecimentos podem atuar conjuntamente.

Como antropólogo yepamahsu (tukano), sou idealizador do Centro e busco articular politicamente e divulgar a experiência da implantação do Centro em todos os níveis nas associações indígenas, nas universidades, nas escolas e na mídia, promovendo debate e diálogo entre a biomedicina e conhecimentos indígenas. Também sou pesquisador e faço exercício de pensar o pensamento indígena, com objetivo de fundamentar teoricamente as concepções e técnicas de tratamento de doenças a partir de epistemologias indígenas. Articular parcerias também faz parte do meu trabalho, além de incentivar diretamente os jovens e especialistas envolvidos no Centro.

\section{COSMOPOLÍTICAS DO CONHECI- MENTO}

Existem vários modos de explicar, entender, organizar e manipular o mundo, que designamos como conhecimento. A ciência, como conhecimento que se pretende universal, organiza a realidade em três grandes reinos, isto é, o reino animal, reino vegetal e reino mineral. Cada reino, por sua vez, é organizado em campos de conhecimentos específicos, como ciências humanas, ciências exatas e ciências biológicas, e são articulados em disciplinas como Sociologia, Antropologia, História, Geografia, Direito, Física, Química, Geologia,
Biologia, Medicina, Enfermagem etc. Essa organização em campos de conhecimentos específicos nada mais é do que o desejo de controlar e separar fenômenos sociais e naturais, de modo a agenciá-los para o benefício político, econômico e social.

Entre os povos do Alto Rio Negro, conhecer o mundo significa necessariamente estabelecer relações cosmopolíticas, sem dividi-las em relações sociais e meio natural. Consideramos que todos os "ambientes" dos espaços aquáticos, terra/floresta e aéreo ${ }^{3}$ são habitados por outros seres humanos, denominados de waimahsã, na língua yepamahsã, que doravante são traduzidos como espíritos. Essa noção de espaços mais inclusiva está articulada com bahsese (benzimentos) e a interação dos humanos como waimabsã, habitantes dos respectivos "ambientes".

A "tradição intelectual" indígena, de ver, de pensar e de organizar o mundo, os seres e as coisas, de relacionar, de manipular e perceber as mudanças, está ancorada numa epistemologia que não é aquela que aprendemos nas escolas e nas universidades convencionais. Ela está ancorada na cosmologia e na cosmopolítica, que são a base de conhecimento e fio condutor de pensamento e das práticas indígenas. Para novas gerações são transmitidas de maneira organizada e sistemática como "teorias de conhecimentos" pelos seus detentores, conhecidos como yai, kumu ou baya.

A relação cosmopolítica, portanto, é um dos princípios básicos para bem viver na concepção dos yepamahsã. Manter uma relação harmoniosa com os 
waimahsã, seres que habitam em todos os espaços cósmicos, que são donos dos lugares e responsáveis pelos animais, vegetais, minerais e temperatura do mundo terrestre é uma necessidade para manter em equilíbrio social e ambiental.

Assim, os yepamahsã têm noção clara de espaço aquático, espaço terra/floresta e espaço aéreo, que por sua vez estão subdivididos em espaços menores, dos quais podem ser entendidos como ambientes. Mais do que espaços de concentração de determinados objetos, seja vegetal, animal ou mineral, os ambientes são definidos e identificados como bahsakawiseri (casas) de waimahsã, tal qual como as moradas dos humanos. Assim, uma cachoeira, uma corredeira, um lago, uma serra, uma floresta de terra firme, um buritizal, ou caranazal, um barreiro, dentre outros, é identificado e organizado como bahsakawiseri (casas) de waimahsã.

Quem são os waimahsẫ? A tarefa de definir ou traduzir os waimahsã é bastante complexa. Uma parte, de acordo com o kumu Ovídio Lemos Barreto, do povo yepamahsã, conta que nos tempos de surgimento, todos os humanos estavam sob condição de waimahsã. Sob esta condição que fizeram a longa viagem de surgimento de humanos. Entretanto, no destino final, na passagem de condição de waimahsã para a condição de humanos, alguns grupos foram preteridos pelo demiurgo Yepa-oãku, mas passaram a habitar nos "ambientes" de todos os espaços do cosmo, com as mesmas qualidades e capacidades dos humanos para serem responsáveis e guardiões das coisas, como vege- tais, animais, minerais, da temperatura, chuva, noite, dia etc.

Eles [waimahsã] só podem ser vistos por um especialista, isto é, yai ou kumu, conhecidos como xamãs. Esses seres são, por fim, a própria extensão humana, devendo sua existência e reprodução ao fenômeno do devir, isto é, a continuidade da vida após a morte, sendo assim a origem e o destino dos humanos, seu início e seu fim. É com estes waimabsã habitantes de diferentes ambientes que os especialistas indígenas se comunicam e adquirem conhecimentos (Barreto 2013).

Assim, todos os "ambientes" do cosmos são habitados por humanos. O bem viver dos humanos, sem doença ou estar bem de saúde, depende da interação e comunicação como esses humanos. Caso não ocorra a comunicação com esses donos dos lugares, que são ao mesmo tempo responsáveis pelos bichos e as coisas, eles podem deferir conflitos sociais, surtos de doenças, escassez de recursos naturais e desequilíbrio ambiental como formas de vinganças. Por essa razão, para o usufruto de qualquer recurso natural ou para ocupação de espaço pelos humanos, é preciso primeiro comunicar-se com esses sujeitos sob mediação dos especialistas yai, kumu ou baya.

Em relação aos humanos, waimahsã são também detentores de conhecimentos primários de kibti-ukuse (narrativas míticas), bahsese (conjuntos de benzimentos) e bahsmori (conjuntos de rituais e práticas sociais). $\mathrm{O}$ acesso e aquisição de tais conhecimentos pelos humanos se dá principalmente durante o período de formação, momento em que 
os neófitos são conectados ao domínio ou às moradas de waimahsã, pelo yai formador, utilizando os elementos kahpi ou wiõ (rapé), como elementos agenciadores. Os professores dos humanos são os waimahsã. Estes possuem uma estrutura de ensino bastante sofisticado, tanto quanto o laboratório. Os humanos necessariamente devem interagir e manter a comunicação com os waimahsã para aquisição de conhecimentos.

Dessa forma, o equilíbrio e desequilíbrio do cosmos, seja ambiental, social e de doenças perpassa necessariamente nas relações entre essas categorias de pessoas, a saber: waimahsã e humanos, que estão conectados num sistema de interdependência, em que cada categoria tem seu tipo específico de conhecimentos e pode atuar indistintamente.

DOENÇAS, TRATAMENTOS E CURAS

O exercício de reflexividade antropológica feito por nós indígenas yepamahsã, do Núcleo de Estudo da Amazônia Indígena - NEAI, em conjunto com os antropólogos não-indígenas e professores, fez-nos concluir que o sistema de conhecimento yepambasã está ancorado em três grandes conceitos abstratos: Kibti-ukuse, Bahsese e Babsamo$r^{4}$, a partir dos quais podem ser organizados campos de conhecimentos mais específicos. Em nossa equipe de pesquisadores desenvolvemos uma obra intitulada Omerõ, que está no prelo, em que os tematizamos.

Resumidamente, Kibti-ubkusse é o conjunto de narrativas míticas que são o resultado das tramas sociais vivenciadas pelos demiurgos e responsáveis pela origem do mundo, dos seres, das coisas, das paisagens (das serras, das cachoeiras, das corredeiras, da floresta/vegetação). Babsesse é quando o kihti-uhkusse é utilizado pelos kumuã para comunicação e interação com os waimahsã, assepsia de alimentos e habilidade de invocar elementos e princípios curativos, contidos nos tipos de vegetais, animais e minerais. Já Bahsamori ${ }^{6}$ é quando o kihti-ubkusse é acessado para composição musical durantes as festas de dabucuri, que envolvem os cantos, danças, instrumentos musicais, práticas agrícolas, práticas de caça e pesca, etc.

Ainda de acordo com nossa pesquisa coletiva sobre conhecimentos os indígenas, podemos dividir as causas de doenças entre aquelas causadas pelos ataques de Waimhasãa; aquelas causadas pela alimentação; doenças autoprovocativas e sonhos; e por fim agressões interpessoais ou feitiçaria.

Como comentado, os ambientes são considerados casas de waimahsãa, que são responsáveis pelos recursos naturais de seu entorno e aos animais que circulam nos ambientes. Para utilizar tais recursos, os humanos necessariamente devem negociar com os waimahsã, caso contrário esses seres deferem ataques contra a pessoa, utilizando os meios como picada de cobra, acidente fatal e doenças que podem ser mortais. Para circular nos ambientes, os humanos devem pedir licença desses donos dos lugares, sobretudo nos momentos mais vulneráveis da vida, como no período de gestação, menstruação, etc. $\mathrm{O}$ 
mais importante bahsero (benzimento) é o wetidareró, para estas situações.

Wetidarero é uma arte de comunicação com os humanos invisíveis, formulado pelo especialista, com o objetivo de evitar os ataques dos waimahsã, especialmente naqueles momentos mais vulneráveis, e quando as pessoas se deslocam para os diferentes lugares (habitação de waimahsã) para a prática de pesca, caça e coleta. Os elementos utilizados como veículo de comunicação nesses casos são o cigarro ou o urucum.

Outra fonte de doenças são os alimentos, seja animal, vegetal e frutas. Toda comida é portadora em potencial de doenças, pois são carregadas de microrganismo capazes de atacar a saúde humana. Para isso, as frutas devem passar por processo de assepsia feito por meio de babsese (benzimento) pelo kumu (pajé).

Essa categoria é chamada pelos Tukano de Baábokasé (doenças causadas pelo alimento). Isso ocorre no consumo waikurã (animais), wai (peixes) e yok u dubka (vegetal). Por exemplo, consumir baá \baáse (comida \alimentos) depois de momentos senviveis e de maior vulnerabilidade como após uso de plumas, de resguardo pré ou pós-parto, após terem visto e terem contato com miria (jurupari). Uma das recomendações principais é de moderação no consumo de certos alimentos que contem certos elementos, como peixes e carnes de caça, que contêm muita $u$ sé (gordura), metafisicamente estas gorduras ficam impregnadas (useesãse) no corpo da pessoa que ingeriu: no sangue, no estômago, no fígado, no coração, nas veias, na pele e na carne, useesãse, as gorduras invisivelmente impregnadas, fazem surgir e aparecer àquelas kamibuku (feridas e infecções dermatológicas) que podem vir a serem incuráveis. De mesma forma, o consumo e a ingestão de frutas da roça ou do mato consideradas usekuose (oleosas e gordurosas) como açaí, patauá, buriti, umari, inajá, ucuqui, cunuri, uacu, provocam também este fenômeno de useesãse impregnação das gorduras e causam kamibuku.

Outra recomendação importante é a moderação no consumo de puõbaase (assados) e tãbaase (assados ou enterrados na brasa embrulhados com folhas) que pode causar, além do kamibuku visto como nos casos precitados, uma série de omeperi bususe (distúrbios auditivos), wisisé (salivação excessiva noturna), dipetisé (palidez excessiva), puapetisé (emagrecimento), dimehã (obesidade), kematise (sonhos estranhos), witõda unhsé ("queima da massa encefálica") e matisé (loucura).

Outra forma de causa de doenças é autoprovocação do corpo, sobretudo nas mulheres. No período de sua menstruação ou gestação, a mulher pode contrair doenças. Para evitar as complicações as mulheres devem se submeter à prevenção, adotar dieta, adotar certos comportamentos específicos e ficar sob cuidados do kumu.

As doenças do descuido poder ser do útero, doenças do fígado, da mama, da garganta, feridas e coceiras no corpo, além de doenças como fogo selvagem. A mais grave pode ser a gestação de 
criança deficiente. Além disso, podem ter dificuldade de ter parto natural. Para tudo isso tem bahsese (benzimentos) específicos.

Há ainda doenças que são causadas por agressões interpessoais, vulgarmente conhecido de feitiçaria. useró pehtise é um assunto complexo e delicado, de modo que mesmo aqueles que sabem e tem conhecimentos não estão dispostos a contar, comunicar, comentar e informar os não-especialistas sobre o tema, para não revelar como se formula e faz esta categoria avessa do conjunto dos bahsese, mas se limitam em indicar o que acontece com a vítima e possíveis sintomas. Nesse sentido, quase todos conhecem as doenças provocadas por useró pebtise, mas nem todos conhecem o tratamento e a cura, somente alguns especialistas. Os especialistas afirmam que a pessoa com habilidade de agressão por meio dos bahsese, tem uma vida curta, na medida em que, o agressor pode ser atingido com weopeose e bia doase ("antidoto de feitiçaria") de sua própria agressão.

\section{OS ESPECIALISTAS YEPAMAHSÃ}

Nas sociedades indígenas do alto Rio Negro existem três categorias de especialistas, yai, kumu e baya, que são agenciadores cósmicos e cosmopolíticos. São sujeitos que passaram por uma rigorosa formação e treinamentos, sob orientação de especialista formador. Conectando no domínio de waimabsã, adquiriram kibti-ukuse, bahsese e bahsamori, conhecimentos considerados fundamentais para a existência humana.
O yai, kumu e baya são como detentores de Babsese. Para efetuar tratamento, antes de tomar qualquer providência, os especialistas, primeiro fazem diagnósticos através de séries de perguntas. O objetivo é descobrir exatamente a origem e causa da doença. Feito o diagnóstico, lança mão dos bahsese especifico para curar aquela doença. Os elementos utilizados podem variar entre tabaco, breu (enzima vegetal), água, chá e outros como perfume, gel etc. Como dito acima, bahsese é habilidade de invocar elementos e princípios curativos, contidos nos tipos de vegetais, animais e minerais sobre os elementos para ser tratado o paciente.

Já a utilização de plantas medicinais na atenção à saúde que pode ser vegetal da mata e planta do quintal. Não é qualquer pessoa que domina as plantas. Isso também requer formação, conhecimento e habilidade para manipular a planta para ter poder de cura de doenças.

Os especialistas yai, kumu ou baya são humanos e quase demiurgos, pois pautam-se como extensão de demiurgos, seres que deram origem à plataforma terrestre, floresta, rios, animais, vegetais e minerais. Os demiurgos também deram origem aos waimahsã e humanos como sua extensão de vida, dotando-lhes de capacidades e costumes específicos. Foi por meio de bahsese que os demiurgos fizeram surgir todas as coisas. Assim, aquele que domina kihti-ukuse-bahsese-bahsemori possui capacidade de recriar, reorganizar o cosmos e manipular suas partículas para o bem ou para o mal. 
O nome adotado pela pessoa é fundamental para se tornar especialista, pois traz a presença da potência criadora $e$ mantenedora de tudo quanto há, ou seja, kibti-ukuse-bahsese-bahsemori. O domínio desses conhecimentos coloca o especialista no patamar de recriador, mantenedor ou destruidor, tal qual como os demiurgos versados nas narrativas míticas. Outro fator importante da nominação é sua capacidade de inserir a pessoa na estrutura cosmológica e cosmopolítica, além de conferir entre seus pares uma função social. Dito de outra forma, o nome é omerõ (força), uma potência que pode ser desenvolvida pela pessoa para ser bom especialista.

[Omerõ] está intimamente relacionado ao conjunto dos babsese e aos modos de ação do especialista yepamahsã: kumu, yaí, baya e bahsegtt. Omerõ diz respeito a força do coração, força da mente e também a força que o especialista mantém no seu corpo para então lançar mão dos bahsese. A origem dessa força (capacidade de criar ou destruir) está diretamente ligada a Bubpo, sendo que este é considerado o próprio omerõ. Desse modo, essa força existe desde da origem dos Yepamahsã narrada no conjunto dos kibti ukuse. A potência do ómero no coração está relacionada ao ato de realizar o babsero de coração do recém-nascido (heriporã babsese), que consiste na comunicação do especialista com Yepa Oãku para que seja lançado mão do nome da criança. Este nome é extraído de um repertório conhecido e fechado de no- mes yepamahsã, que por sua vez vão ser dados de acordo com as potencialidades e características inerentes a criança (calma, agitação), sendo anunciado de Yepa Oãku para o especialista. No ato de dar o nome no momento do beriporã bahsese, a criança não só está interligada a estrutura cosmológica yepamahsã, como também, adquire o seu ómero, que por sua vez é um fragmento do omerõ do próprio Yepa Oãku. Isso possibilita aos Yepamahsã acionar os diferentes tipos de babsese, podendo assim interagir com os waimahsã e também com os seus semelhantes. Assim, o nome dado a partir do heriporã babsese é o próprio omerõ. Acerca do omerõ designado como potência da mente e também como força que o especialista mantém no seu corpo, refere-se a essa força direcionada para realização do bahsero. O ómero localiza-se na porta da boca do especialista, com essa força juntamente com a intencionalidade do especialista, a utilização das narrativas, das classificações e também do murupu nkuse, o sopro adquire os atributos de cura e de comunicação entre os Yepamahsã e os waimahsã e comunicação dos humanos entre si. (Omerõ et alli 2016. no prelo).

$\mathrm{Na}$ teoria, toda pessoa yepamahsu (singular) tem potencialidade de ser especialista, mas isso tem preço. Tradicionalmente, o cuidado do corpo para ser especialista começa logo após o parto, a criança recém-nascida é cercada de cuidados pelos seus pais que se sujeitam a severas regras e in- 
terdições. Nesse período, a criança recém-nascida depende da conduta dos pais para que os waimahsã não os agridam.

Quando passa essa fase, o cuidado passa a ser pessoal, com a reclusão e um rigoroso regime de controle alimentar e sexual, além de submeter ao acompanhamento do yai mais experiente. Depois dessa investida, é ativado o poder, a força, o omerõ. Isso conecta a pessoa definitivamente na estrutura cosmológica e cosmopolítica, isto é, ao domínio dos demiurgos e dos waimahsã, com os quais passa a se comunicar e interagir.

O investimento do corpo é a base para ser bom especialista. O corpo é preparado com investimentos de adereços que não são visíveis a pessoas comuns. Essas são condições para expandir-se para qualidade de "original", próximo aos demiurgos e waimahsã, se tornando pessoa com força de invocar elementos e princípios curativos, contidos nos tipos de vegetais, animais e minerais para tratar as doenças, de modo a transformar determinados elementos (água, tabaco, enzima vegetal, entre outros) em agentes protetivos e curativos, além da habilidade de provocar os fenômenos naturais como raios e trovoadas e usar qualidades de animais para determinadas finalidades.

Outra função do especialista é promover diálogo constante com os seres waimahsã visando manter o cosmos equilibrado, com condições habitáveis aos seres humanos. Assim, a relação entre os humanos e os waimahsã se fundamenta no intercâmbio recíproco de vitalidade. Se o intercâmbio for violado, pode acontecer o desequilíbrio social, político, econômico e ambiental. Para isso, os especialistas aparecem como o principal meio de comunicação com os seres de diferentes domínios e espaços.

Portanto, o desequilíbrio é entendido como um conjunto de manifestações "anormais" que compromete negativamente a organização cosmológica e cosmopolítica, afetando a vida social, política, econômica e ambiental. Tal desequilíbrio pode se manifestar sob formas de surtos de doenças, acidentes de grandes proporções, conflitos sociais, guerras, nascimento de muitas crianças com deficiência física ou mental, grandes impactos de fenômenos naturais, escassez de recursos naturais, desequilíbrio de bioindicadores, entre outros fenômenos anormais.

Uma vez, no ano de 2016, meu pai, Ovídio Lemos Barreto, a convite de uma equipe de médicos dermatologistas do Hospital Tropical, participou do tratamento de dois pacientes indígenas durante um mês. Nesse período que freqüentava os ambientes do hospital, ele olhava para alguns pacientes, sobretudo as mulheres, e logo dizia que a doença era conseqüência de ataque dos waimahsã, ou conseqüência de alimentação, que por descuidos durante seus momentos de maior vulnerabilidade de vida, como período de menstruação, de gravidez ou pós-parto, teria circulado nos ambientes estranhos sem proteção ou se alimentado sem fazer 
bahsese. O kumu Ovídio Barreto fazia diagnóstico do paciente só ao vê-lo. Partindo da noção de contaminação, ia relacionando as doenças com o modo de vida do paciente.

O "mundo" dos waimahsã é o "laboratório", a verdadeira escola dos humanos, um espaço onde os neófitos adquirem conhecimentos, treinamentos, técnicas de diagnósticos e de cura de doenças, antes de exercer o oficio entre seus pares. Assim, diferentemente da noção antropológica comum de que os especialistas são sujeitos que tem capacidade ou dom de se comunicar com os deuses ou com os mortos, eles são líderes espirituais, guardiões de conhecimentos, além de serem formadores de novos especialistas. Acionam os kihti-ukuse, bahsese e bahsamori para resolver problemas cotidianas, seja para cura de enfermidades ou para a reorganização do cosmos, mantendo interlocução com os waimahsã dos domínios aquático, terra/floresta e aéreo, para que suas forças estejam em equilíbrio.

No cotidiano, os especialistas são requisitados para várias finalidades, sobretudo para elaborar os babsese de cura de doenças, para o bahsese de proteção contra os ataques dos waimahsã, para o bahsese de primeiro banho pós-parto, para o bahsese de proteção da moça durante a primeira menstruação, para o bahsese de proteção da casa, da família, do trabalho e contra o ataque dos inimigos. São acionados ainda para a elaboração de bahsese de assepsia de alimentos ${ }^{7}$, para o babsese de feridas, para babsese de doenças do seio (mama), para o bahsese de diarréias, para dor de cabeça, dor de barriga, dor de dentes, dores musculares etc.

Os especialistas também podem ser acionados para "infernizar" a vida de seus desafetos, podendo provocar a aceleração de partículas para atacar ou contra-atacar, por exemplo, ao invocar raios e trovoadas de grande intensidade sobre uma casa ou sobre uma pessoa. Podem também acionar os bichos, sobretudo as cobras venenosas, para atacar um inimigo. Outra possibilidade de ação do especialista é o uso de "roupa" (sutirô) de predadores para certas finalidades.

Minha experiência pessoal foi ter meu avô paterno, yai, chamado Ponciano yai, como interlocutor quando era "adolescente". Ele me contava suas aventuras de especialista e como acionava as partículas ou fenômenos naturais para atacar seus desafetos. Assim fez até estar à beira de sua morte. Atualmente tenho meu pai, o kumu Ovídio Lemos Barreto, como seu sucessor. Outro ${ }^{8} k u m u$ é meu tio, Manoel Lima, Tuyuca, e o meu irmão José Maria Barreto está a caminho de se tornar kumu. Os três atuam no Bahserikowi'i.

O centro acabou de ser inaugurado e ainda não sabemos como será seu futuro, mas nossa intenção é que ele possa fortalecer os conhecimentos indígenas nos conflitos ontológicos com a medicina, mas fortalecendo também as alianças possíveis para tratamentos que possam articular essas diferentes formas de curar e viver. 


\section{NOTAS}

1 Indígena do povo Yepamahsã (Tukano), nascido na aldeia São Domingos, no município de São Gabriel da Cachoeira (AM). Graduado em Filosofia, Mestre e Doutorando em Antropologia Social pelo programa de Pós-Graduação em Antropologia Social da Universidade Federal do Amazonas. Pesquisador do Núcleo de Estudos da Amazônia Indígena (NEAI) e Idealizador do Centro de Medicina Indígena.

2 Quero agradecer ao Professor Gilton Mendes dos Santos e a Professora Valéria Macedo pelo apoio e incentivo para escrever este texto. Trocas de idéias e suas sugestões foram fundamentais para a construção do texto.

${ }^{3}$ A concepção de organização de espaços cósmicos, como espaço aquático, terra/ floresta e aéreo foi em minha Dissertação de Mestrado (autor 2013). Nesse trabalho, apenas o espaço aquático foi trabalhado com detalhes, como base para a discussão da presença dos waimahsã no universo aquático. Posteriormente, o espaço terra/ floresta foi trabalhado por Dagoberto Azevedo (2016) e o espaço aéreo por Gabriel Maia (2016).

${ }^{4} \mathrm{Um}$ exercício de reflexividade coletiva de um grupo de estudantes indígenas de pós-graduação em Antropologia Social, no âmbito do projeto Rios e Redes, desenvolvidos pelo Núcleo de Estudo da Amazônia Indígena-NEAI, permitiu conceituar os conhecimentos Tukano em três grandes campos de conhecimentos, que são Kibti-ukuse, babsese e babsamori, doravante denominamos de trindade por razão de ser uma coisa indivisível do ponto de vista dos especialistas indígenas Tukano. O resultado dessa pesquisa conjunto vai ser publicado com o Título: OMERÕ - Constituição e circulação dos conhecimentos Yepamahsã (tukano) (no prelo).

${ }^{5}$ Babsese foi trabalhado pelo Dagoberto Azevedo (Tukano) em 2016, na dissertação de Mestrado, com uma riqueza de detalhes sobre os conjuntos de babsese (benzimentos) acionados pelos especialistas indígenas nas suas experiências cotidianas, seja para comunicar com os seres que habitam nos domínios da terra/ floresta, a assepsia de alimentos e babsese para acionar princípios curativos e protetivos.

${ }^{6}$ Babsamori foi trabalhado pelo Gabriel Sodré Maia (Tukano) em 2016, na dissertação de Mestrado, no qual trata das práticas sociais dos povos indígenas do Alto Rio Negro as práticas sociais, doravante denominados de rituais, acompanhando o calendário cosmológicos e seus bioindicadores. Mostrando que as práticas sociais são meios de atualização e circulação de conhecimentos.

${ }^{7}$ Para os povos indígenas do alto Rio Negro, todos os alimentos - frutas, peixes, caça, até mesmo a água são tidos como veículos de doenças que necessariamente devem passar pela assepsia para neutralizar o potencial de causar as doenças.

\section{REFERÊNCIAS}

Azevedo, D.L. 2016. Forma e Conteúdo do Bahsese Yepamahsã (Tukano): Fragmentos Do Espaço Di’Ta/Nuhku (Terra/Floresta). Dissertação de Mestrado, Antropologia Social, Universidade Federal do Amazonas, Manaus-AM.

Barreto, João Paulo Lima. 2013. Wai-Mahsã: Peixes e Humanos - um ensaio de Antropologia Indígena. Manaus, dissertação de mestrado/PPGAS - UFAM. 
Barreto, J. P. L.

Maia, G.S. 2016. Bahsamori: o tempo, as estações e as etiquetas sociais dos Yepamahsã (tukano). Dissertação de Mestrado, Antropologia Social, Universidade Federal do Amazonas, Manaus-AM.

OMERÕ, 2015 - Constituição e circulação dos conhecimentos Yepamahsã (tukano) (no prelo). 